\title{
The chemistry of profits
}

from Nechemia Meyers, Rehovot

Detailed plans are now being made for an investment of some $£ 240$ million in Israel's chemical industry. Roughly half this sum will be used to promote the exploitation of inorganic Negev chemicals, with the other half being used to expand the Haifa Bay complex of petrochemical firms.

The investment, enormous in Israeli terms, is a natural outcome of the chemical industry's growing success, both in supplying vital products to the home market and in the export sphere. Overseas sales of Israeli chemicals already account for $20 \%$ of her industrial exports (excluding diamonds), and there is no apparent limit to potential customers.

The 393-square-mile Dead Sea, most saline of the world's lakes, has long been the major focus of Israel's chemical industry in the 20th century. Plans for exploiting its potash and other mineral resources were drawn up in 1911 by Moshe Novomeysky (an immigrant from Siberia) and the first plant, run by Novomeysky, began operation in 1931. For many years, however, the Dead Sea Works were usually in the red, causing cynics to suggest that "the only thing that can sink in the Dead Sea is money".

It sinks no longer. On the contrary, Dead Sea potash, bromine and magnesium oxide-extracted from a 50square-mile area of evaporation pans at the southern end of the saline lake whose waters initially contain only $1 \%$ (by weight) of potassium chloride-are today sold at a handsome profit to customers in Europe, Africa and the Far East.

Other Negev enterprises are also profitable, in large measure because of rising prices. Israel's phosphate mines-part of the Mediterranean phosphate belt that stretches from Morocco in the west to Jordan in the east and Turkey in the north-are a striking case in point.

In 1971 Government experts, dismayed bv 20 years of losses, suggested that they be closed down. Fortunately they were not, and as a result profits are now rolling in to the State Treasury. Ironically, they largely reflect Arab Morocoo's successful exploitation of the world-wide fertiliser shortage to push up phosphate prices from $\$ 11$ to $\$ 60$ a ton in just one year.

Copper prices are now lower than they were at their peak, but they are still high enough to ensure the profitability of the modern copper mines at Timna (which are very near the Chalcolithic ones). However, the copper-

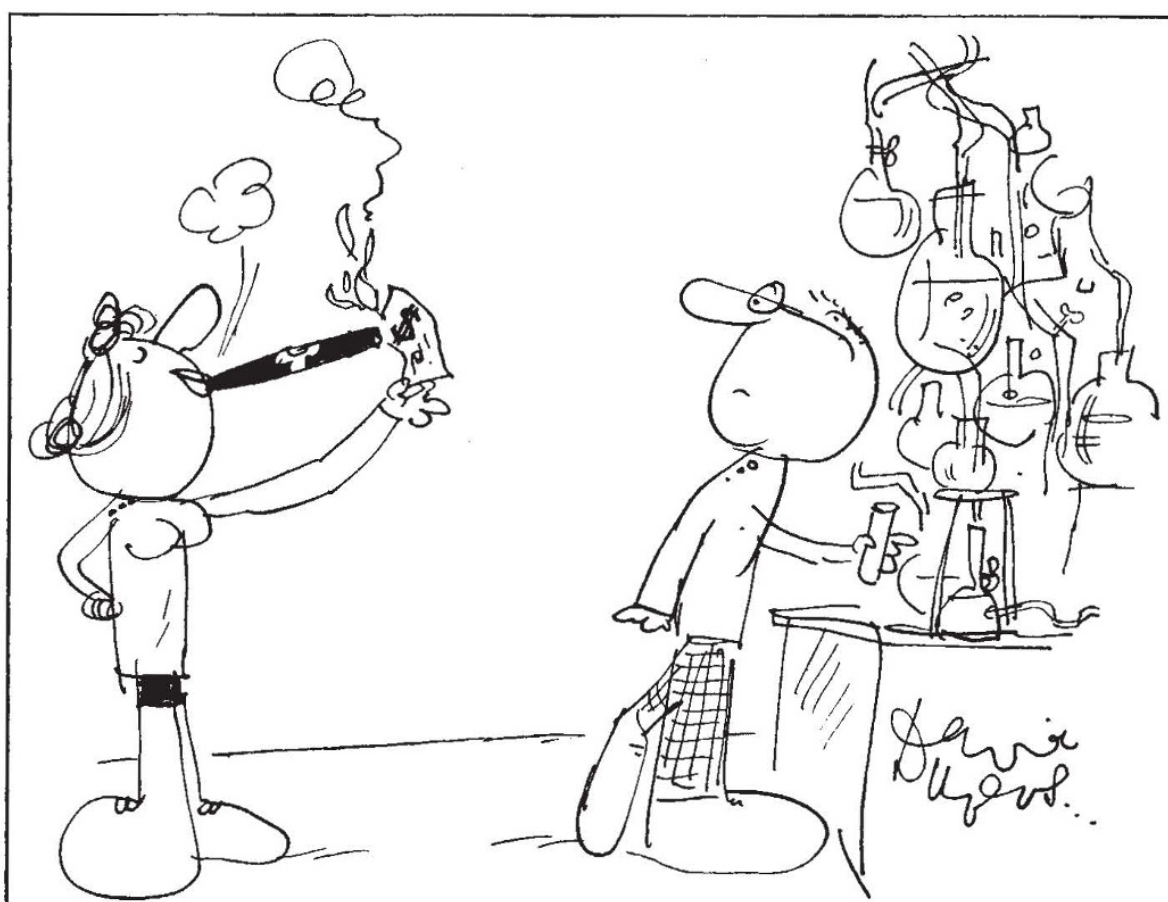

WOMEN who graduated from American universities this year with a degree in chemistry or chemical engineering commanded higher salaries than their male counterparts, according to a study carried out by the American Chemical Society. It is the first time since the society began keeping track of such matters that women graduates have earned more than men.

The ACS survey showed that, on average, the starting salary for women chemists this year was $5 \%$ higher than that for men, whereas in 1964, newly graduated women chemists could expect to earn only $68 \%$ of the starting sa!ary for men. While this seems to

bearing strata that were worked in ancient times are not the same as those mined today. Formerly copper nodules associated with fossilised trees within the Middle White Sandstone were exploited. This layer appears near Timna about 330 feet above the copper-bearing Cambrian rocks that are now worked (by both underground and open-cast mining).

The only major failure in this sphere has been with a controversial plant, near the Judean Desert town of Arad, for the manufacture of phosphoric acid by means of hydrochloric acid produced from residual Dead Sea brines. An American firm whose fluidised refining process was used in the plant, the Madera Company, is being sued in an attempt to recover at least part of the $£ 25$ million loss, and alternative operating methods are now being studied.

When the current expansion plan is completed, potash production will rise from one million to 1.5 million tons a year, phosphate production from one indicate that employers are attempting to recruit more women, the survey also turned up evidence that the battle for equal employment opportunities still has some way to go. For one thing, women and minority groups had a higher unemployment rate than the average for all ACS members. The overall rate of $1.4 \%$ was exceeded by American Indians (6.3\%), Orientals $(3.1 \%)$, Spanish surnamed and black chemists $(1.5 \%)$, and women $(3.5 \%)$. But at least that's an improvement on previous years, when the unemployment rate among women chemists was typically running at about three times that for men.

million to 2.8 million tons a year and bromine production from 20,000 to 50.000 tons annually. Profits from the mining and processing of Negev chemicals, this year expected to total $£ 15$ million, will presumably also rise in at least the same measure.

The scheduled $£ 240$ million investment in the petrochemical industry will meet local needs for petrochemicals (including raw materials for plastics) and also give a boost to exports. Items whose production is to rise include polyethylene, styrene, polystyrene, phenolics and PVC. In addition, much larger quantities of potassium nitrate - a highly regarded, Israeli-developed chemical fertilizer-will be produced in the Haifa area.

While the cost of the oil used as a base for these petrochemical products has obviously risen steeply, Israel is no worse off in this respect than her comnetitors, and looks ahead to profits from petrochemicals in addition to those she is already earning from inorganic chemicals. 